\title{
DENSITY ANALYSIS OF LINEAMENTS USING REMOTE SENSING DATA
}

\author{
Sichugova L.V. . $^{*}$ \\ ${ }^{1}$ Junior researcher, Astronomical Institute of the Uzbekistan Academy of Sciences \\ Uzbekistan, Tashkent
}

Fazilova D.Sh. ${ }^{2}$

${ }^{2}$ Doctor of Physical and Mathematical Sciences, Astronomical Institute of the Uzbekistan Academy of Sciences Uzbekistan, Tashkent

\author{
Mukhtorov N.M. ${ }^{3}$ \\ ${ }^{3}$ Engineer, Astronomical Institute of the Uzbekistan Academy of Sciences Uzbekistan, Tashkent, \\ "Corresponding author: Lola Sichugova
}

Article DOI: https://doi.org/10.36713/epra5613

\begin{abstract}
Lineament analysis is an important structural and geological indicator for determining general and local tectonic trends and fracture zones in rocks, especially in mining zones. In this study we used optical and radar satellite data to analyze the density map of lineaments structure data for territory of Kashkadarya region - one of the main gas producing regions in Uzbekistan. The results show that according to Landsat 8 high density of lineaments is located near geology faults. During a detailed exploration, the density map according to SRTM data found that at an azimuth of $180^{\circ}, 225^{\circ}, 270^{\circ}$, and $315^{\circ}$ the density is much higher than at an azimuth of $0^{\circ}, 45^{\circ}, 90^{\circ}$, and $135^{\circ}$.

KEYWORDS: lineaments, optical and radar data, density map, hillshade, rose-diagram
\end{abstract}

\section{INTRODUCTION}

In recent years, interest in the use of Earth remote sensing data in applied research in earth sciences has increased in many countries. Analysis of the results of scientific research to solve geological, natural resource and environmental problems showed that the method of the lineament analysis is one of the most popular methods for thematic analysis of the spatial structure of the earth's surface. This method can be effectively used to detect and monitor linear structures of various natures displayed on space images of the earth's surface. Lineaments reflect underground phenomena occurring as a result of different deformation processes. Spatial properties of lineament structures such as orientation, length, and density can provide important information to demarcate the groundwater potential zones. Traditional methods of ground mapping are ineffective due to the complexity and time consumption for studies of the geological structural features in unreachable mountain areas. Therefore, it is advisable to use automatic methods, less timeconsuming approaches to geological mapping of regions using remote sensing data, and GIS technologies.

A previously published scientific paper has used different interpretation methods. Thannoun (2013) presents a method for processing the extraction of lineament structures using the Edge enhancement algorithm. The method was chosen to use directional filters to improve, extract, and classify 
the orientations of the lineaments [1]. Ni C (2016) et al., were developed a computer program in Matlab to analyze the lineament lengths and densities. The results provide significant advances in the field of ore body exploration [2]. The use of such software tools as LESSA, LEFA makes it possible to automatically search for linear elements and analyze their orientation and location, and also their density [3, 4]. PCA Geomatica software includes a special LINE module. The algorithm of this module consists of three stages of automatic processing: edge detection, threshold determination, and curve extraction [5]. The most widely used spatial analyst hillshade tool in a tectonically active region using radar data [6].

This research aimed to analyze the density map of lineaments structure getting from Landsat 8 and SRTM.

\section{STUDY AREA}

Kashkadarya region is located in the southern part of Uzbekistan in the Kashkadarya river basin, on the western slope of the Pamir-Alay Mountains. The South Tien Shan, South Kyzylkumu-Gissar, Bukhara-Gissar, Poperechno Tien Shan, and other large faults are located in the territory of the Kashkadarya region. The region occupies one of the first places in the country for the extraction of hydrocarbons (oil, gas, and condensate) and the processing of natural gas. The digital elevation model with tectonic faults of the Kashkadarya region is shown in Figure 1.

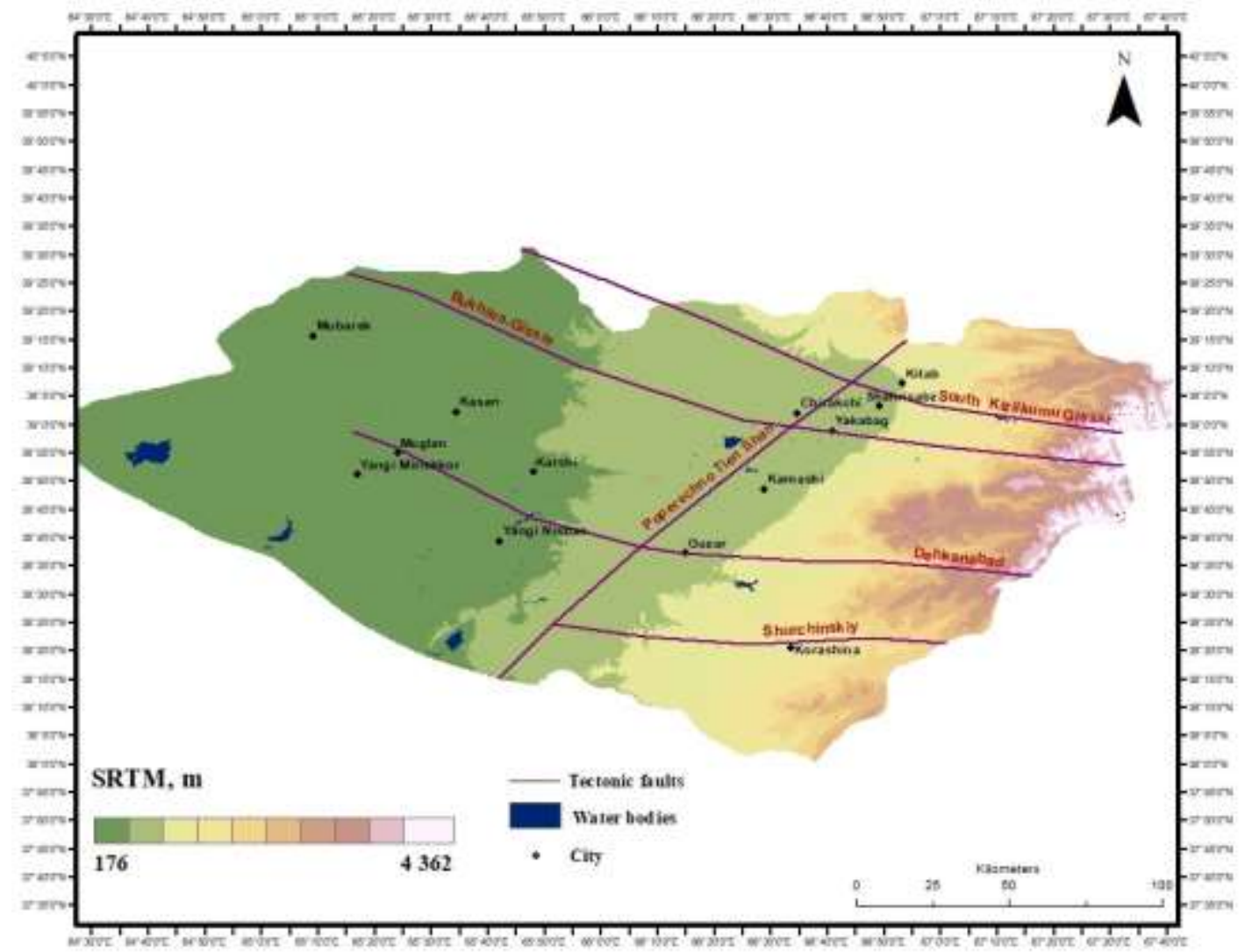

Figure 1: Digital elevation model (SRTM) with tectonic faults (geological data).

\section{MATERIALS AND METHODS}

The study area includes the satellite dataset a mosaic of three scenes of Landsat 8, and a mosaic of seven scenes of SRTM (Shuttle Radar Topography Mission). In this study, Landsat 8 and SRTM scenes covering the study area were downloaded from the USGS Earth Explorer website. The Red, Green, Blue, IR channels of the Landsat 8 data with a spatial resolution of $30 \mathrm{~m}$ were used. The acquisition date of the provided Landsat 8 data is August 2019. A SRTM 1-arc second elevation data product was used. Mosaic of the Landsat 8 satellite was combined with a panchromatic channel $(15 \mathrm{~m})$ to improve the quality of optical data resolution. At the output, we have got a synthesized image with a resolution of $15 \mathrm{~m}$. The tool Create Pan-sharpened in ArcGIS has been used for merging lower quality raster image with a higher quality panchromatic raster layer. Then, based on the obtained image was the extraction of lineament structures was carried out in the LEFA program.

The hillshade method was applied to SRTM to extract lineament structures in the study area. Its principle of operation is to set the position of a hypothetical light source and calculate the azimuth 
values $\left(225^{\circ}, 270^{0}, 315^{\circ}\right.$ и $\left.360^{\circ}\right)$ [7]. In this study, we applied the hillshade tool to SRTM to create two raster images. The first hillshaded image resulted from combining four images from $0^{0}, 45^{\circ}, 90^{\circ}, 135^{\circ}$ azimuth angles (fig. 2, a), and the second hillshaded image with azimuth angles of $180^{\circ}, 225^{\circ}, 270^{\circ}, 315^{\circ}$ (fig. 2, b). For all images, the altitude angle of the light source above the horizon (height) remained constant at $45^{\circ}$, which is the default in ArcGIS. By combining different azimuth angles into one image, we can get more information about linear objects that will not be noticeable if, for example, we use an image with one azimuth angle [7]. The results show that the visibility of linear structures varies greatly with azimuth changes.

The lineament density parameter was built in ArcGIS using the density tool.

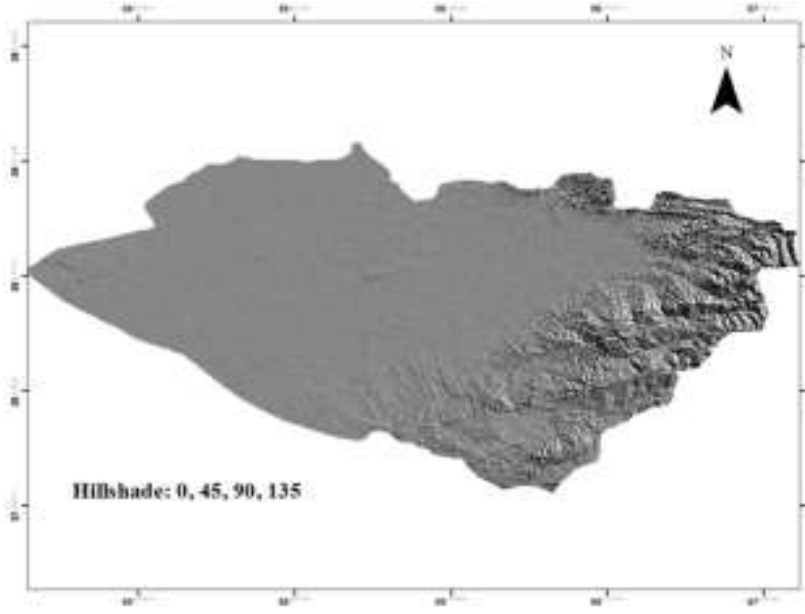

a) Azimuth angle $0^{\circ}, 45^{\circ}, 9^{\circ}, 135^{\circ}$

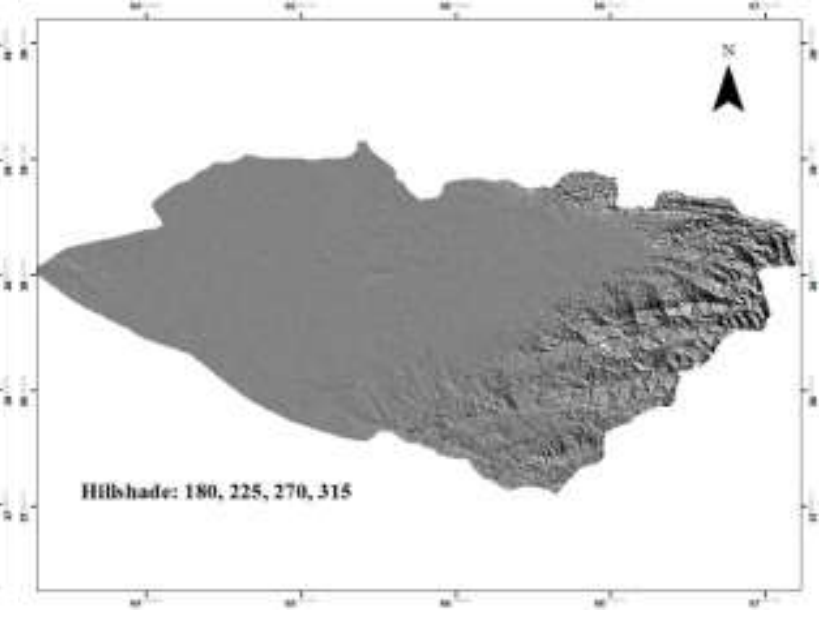

b) Azimuth angle $180^{\circ}, 225^{\circ}, 270^{\circ}, 315^{\circ}$

Figure 2: Hillshaded images

\section{RESULTS AND DISCUSSION}

The LEFA (Lineament Extraction and Fracture Analysis) program, carry out in the MATLAB environment, was used to extract lineament systems from optical and radar data. The LEFA program contains several edge detection algorithms, but the Canny method is most applicable to the study of a linear network. The cracks that form on the surface have degrees of different origins, which are expressed as linear objects. To find them, the Hough transformation is applied to the raster image. In the functional area, the main parameters of the Hough transformation are set [4].

The total count of lineaments according to the Landsat 8 was 302, the minimum length was $1.05 \mathrm{~km}$ and the maximum length was $3.42 \mathrm{~km}$. The main trends indicate two main directions Northwest (NW),
Southeast (SE). Subdominant was also revealed in two directions - northeast (NE) and southwest (SW). Based on the results of the automated processing of SRTM radar data at azimuths of $0^{0}, 45^{\circ}, 90^{\circ}, 135^{\circ}$ were extracted 7049 lineaments with a minimum length of $0.03 \mathrm{~km}$ and a maximum length of $7.01 \mathrm{~km}$. And at azimuth $180^{\circ}, 225^{\circ}, 270^{\circ}, 315^{\circ}$ were extracted 7198 lineaments with a minimum length of $0.03 \mathrm{~km}$ and a maximum length of $7.49 \mathrm{~km}$. It was revealed that the two main directions of the lineaments - WestNorth-West (WNW), East-South-East (ESE) coincide at different azimuths angle.

The density map of the lineaments structure provides information about the concentration of lineaments per unit area [8]. The lineament density maps are derived for the optical, and radar, to analyze the distribution of the lineaments (Fig.3-5). 
EPRA International Journal of Economic Growth and Environmental Issues- Peer Reviewed Journal

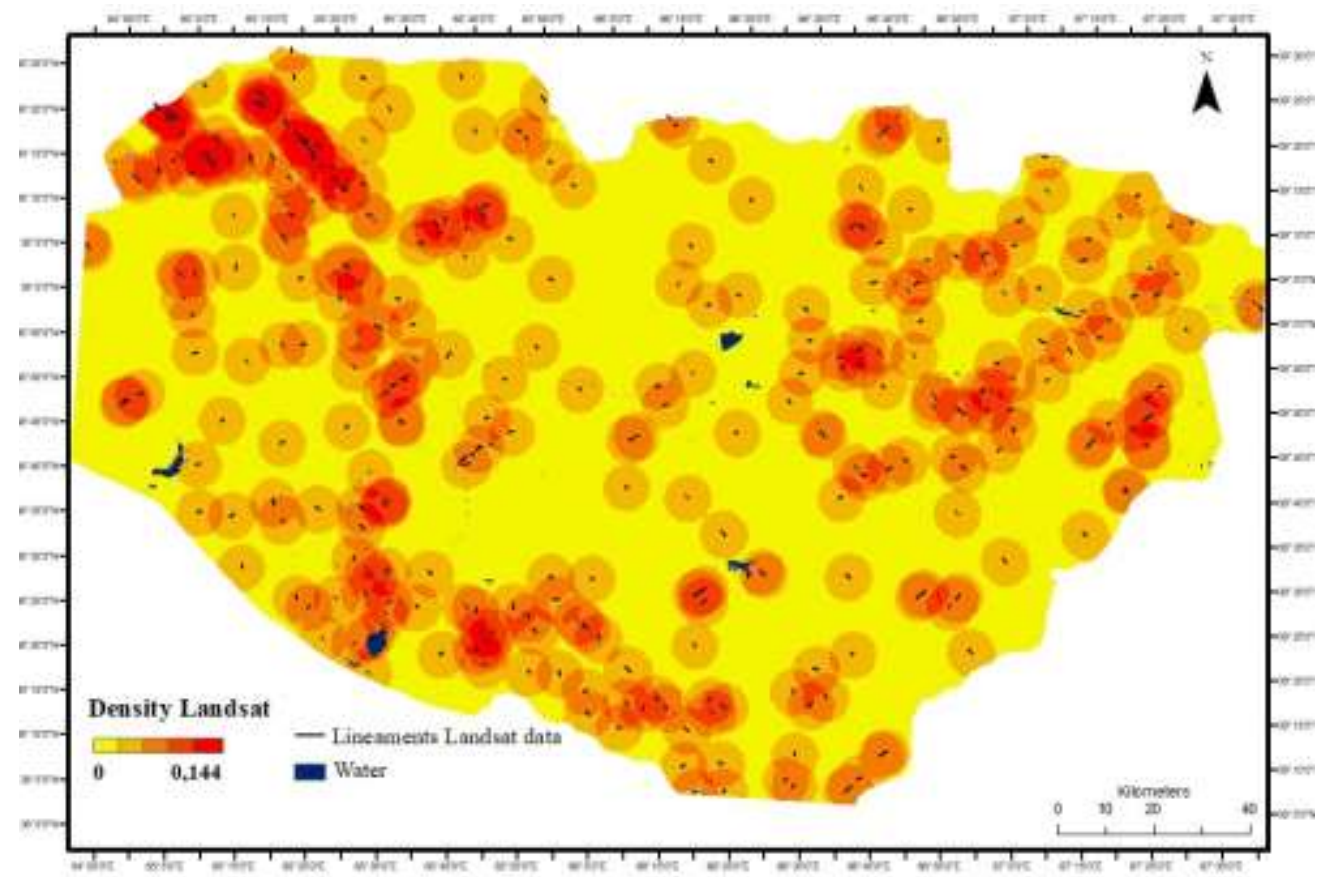

Figure 3: Density map of Landsat 8 data

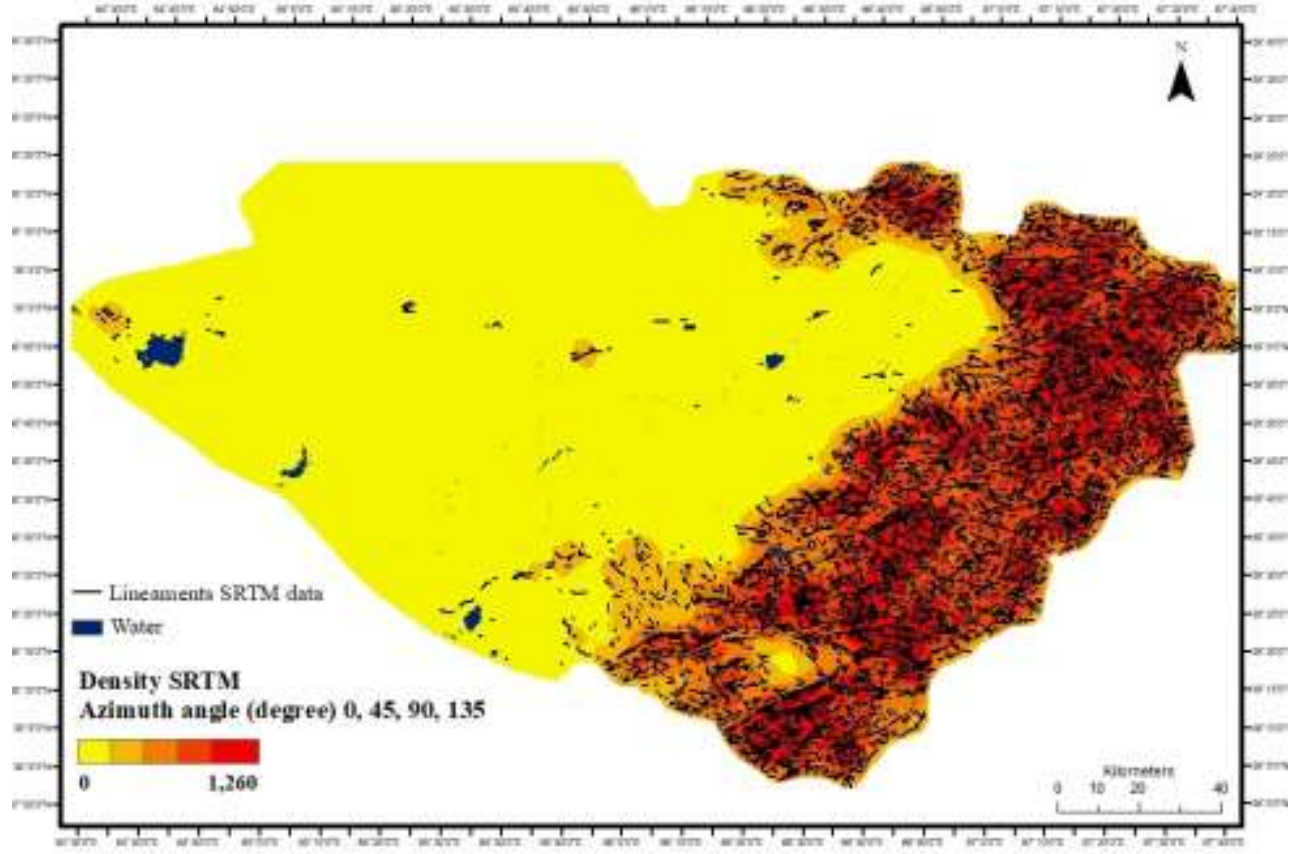

Figure 4: Density map of SRTM data, azimuth angle $0^{\circ}, 45^{\circ}, 90^{\circ}, 135^{\circ}$ 


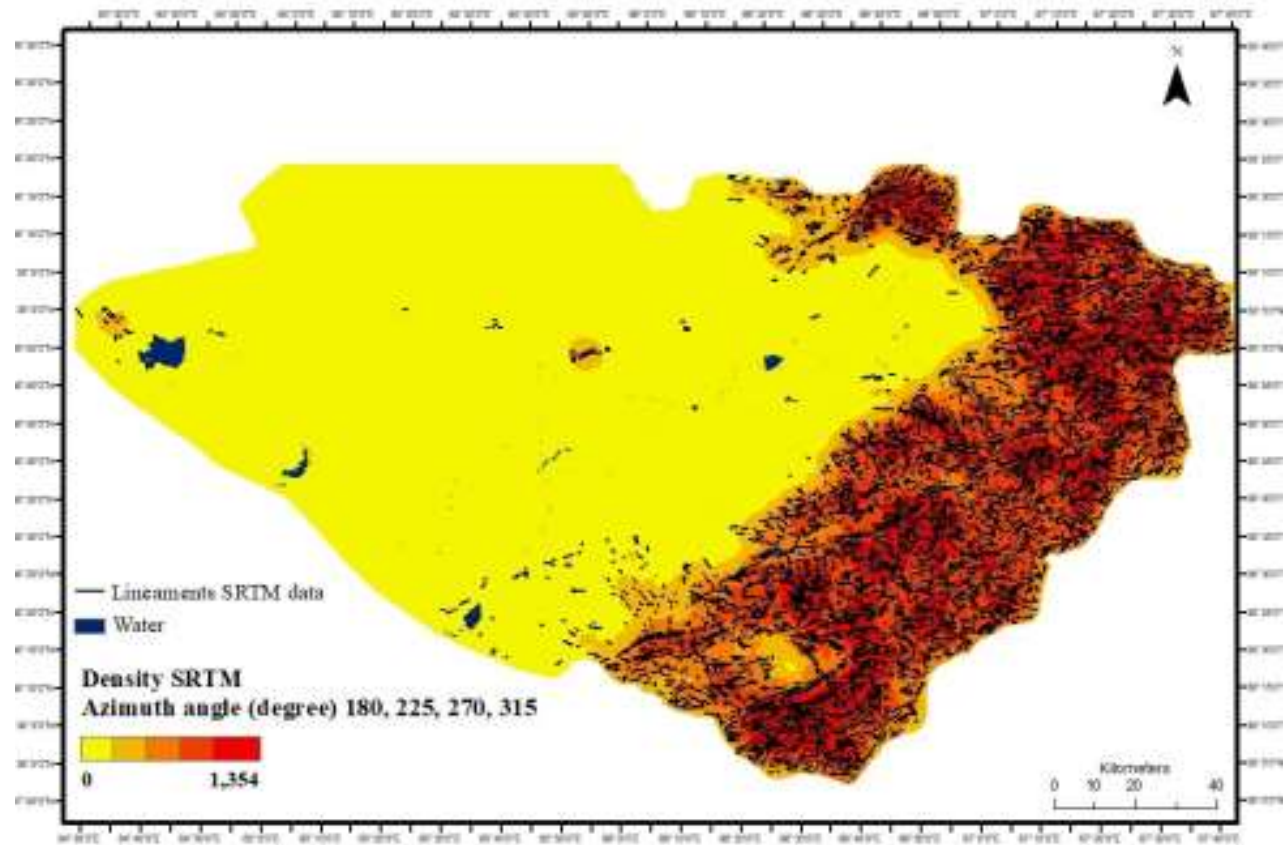

Figure 5: Density map of SRTM data, azimuth angle $180^{\circ}, 225^{\circ}, 270^{\circ}, 315^{\circ}$

Figure 3 shows a density map based on Landsat 8 data. As we can see from the result obtained, the high density of lineaments is located in the north-western part of the study area (Fig. 6 a). According to geological data, the Bukhara-Gissar fault was placed in this region. The length of this fault is approximately equal to $474 \mathrm{~km}$. A lower density is observed in the south-western part of the study area. The accumulations of these lineaments are located near the Jizzakh reservoir (Fig. 6 b). And in the southern part of the region, a low density of lineaments is also observed (Fig. $6 \mathrm{c}$ ). In this part of the region, the density is observed at the intersection of two geological faults of the Poperechno Tien Shan and Shurchinsky, their length is approximately equal to $307 \mathrm{~km}$ and $202 \mathrm{~km}$, respectively.

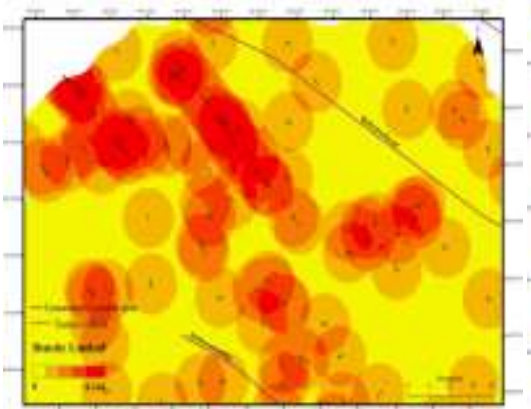

$a$

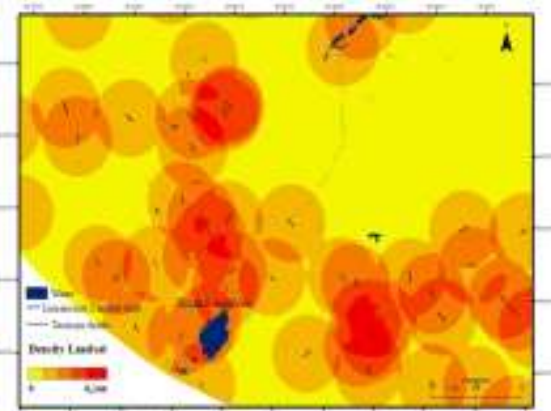

b

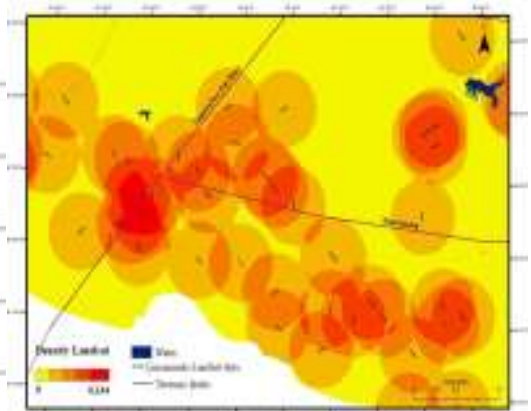

$c$

Figure 6: Detailed of the Landsat density map of the considered region

Figure 4-5 shows the density map according to Landsat 8 data. As we can see from the results obtained, the high density is concentrated in the mountainous terrain of the study area. During a detailed exploration, it was found that:

1. In the eastern part of the area at an azimuth of $0^{\circ}, 45^{\circ}, 90^{\circ}$, and $135^{\circ}$, the density was less than at an azimuth of $180^{\circ}, 225^{\circ}, 270^{\circ}$, and $315^{\circ}$ (fig. 7. a, b). The maximum density in this part of the territory is located on the area of the Dekhkanabad geological fault. The length of this fault is approximately equal to $323 \mathrm{~km}$.

2. In the south-eastern part of the area, changes in density are observed. At an azimuth of $180^{\circ}, 225^{\circ}, 270^{\circ}$, and $315^{\circ}$, the density is much higher than at an azimuth of $0^{0}, 45^{\circ}, 90^{\circ}$, and $135^{\circ}$ (fig. $7 \mathrm{c}$, d). 


\section{EPRA International Journal of Economic Growth and Environmental Issues- Peer Reviewed Journal}

ISSN: 2321-6247

Volume: 8 | Issue: 4 | November 2020 | Journal DOI : 10.36713/epra0713 | SJIF Impact Factor (2020): 8.007

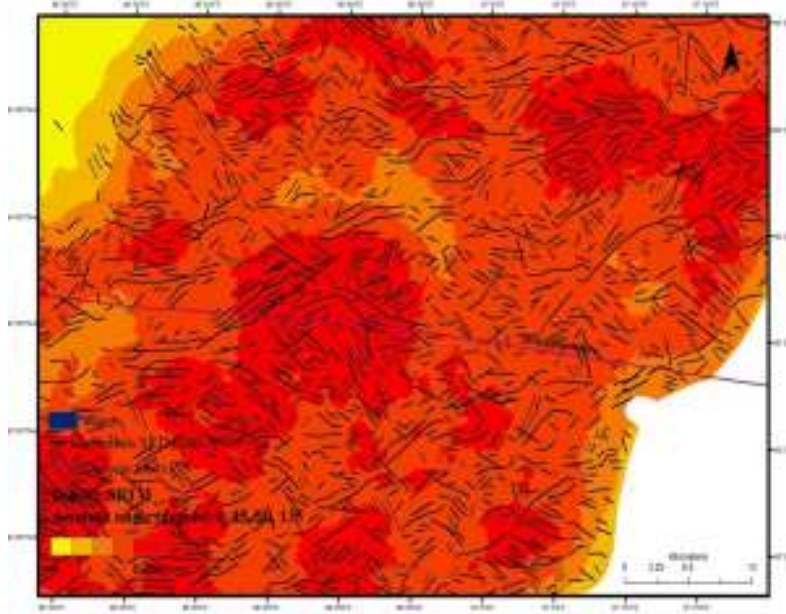

$a$

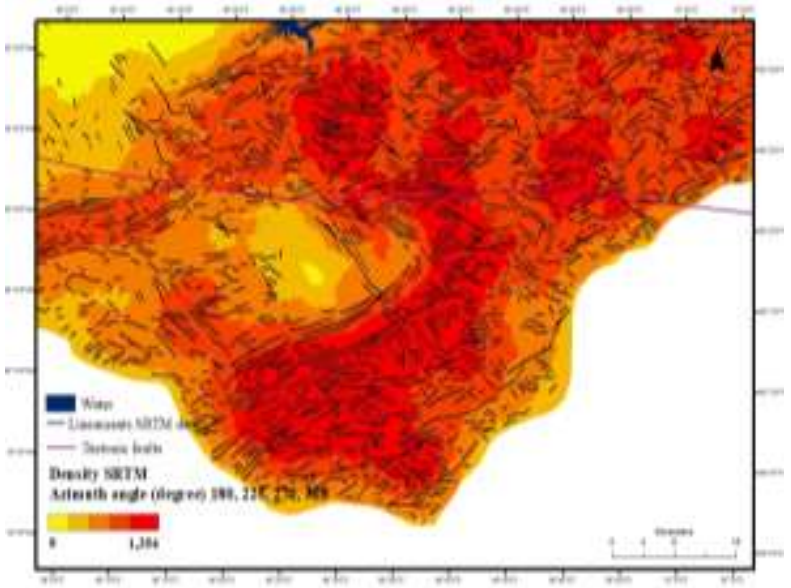

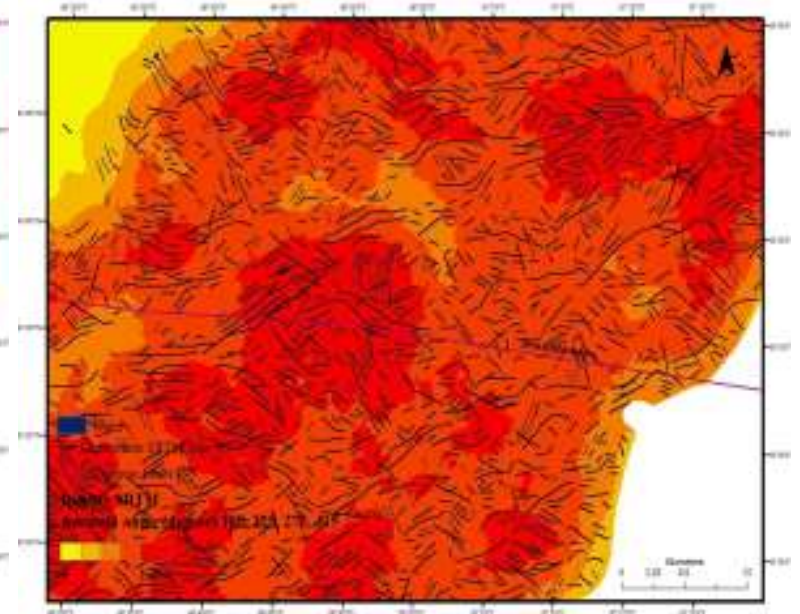

$b$

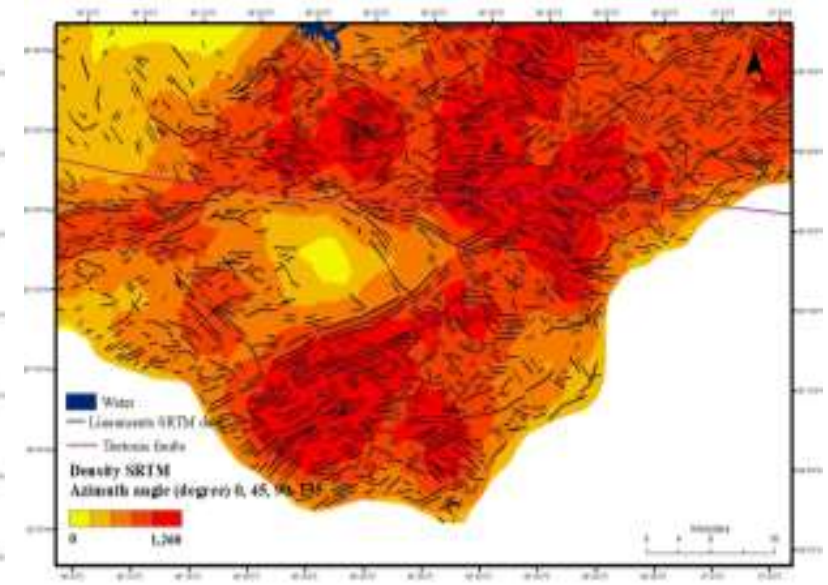

d

Figure 7: Detailed of the SRTM density map of the considered region

\section{CONCLUSION}

This research aimed to analyze the density map of lineaments structure getting from Landsat 8 and SRTM. The results of the density map show that, according to Landsat 8 , the high density of lineaments is located in the north-western part of the study area near the Bukhara-Gissar fault. A lower density is observed in the south-western part of the study area near the Jizzakh reservoir. And in the southern part of the region, a low density of lineaments is observed at the intersection of two geological faults of the Poperechno Tien Shan and Shurchinsky. During a detailed exploration of the density map according to SRTM data found that in the eastern part of the area at an azimuth of $0^{0}, 45^{\circ}$, $90^{\circ}$, and $135^{\circ}$, the density was less than at an azimuth of $180^{\circ}, 225^{\circ}, 270^{\circ}$, and $315^{\circ}$ and the maximum density is located on the area of the Dekhkanabd geological fault. In the south-eastern part of the area at an azimuth of $180^{\circ}, 225^{\circ}, 270^{\circ}$, and $315^{\circ}$, the density is much higher than at an azimuth of $0^{\circ}, 45^{\circ}$, $90^{\circ}$, and $135^{\circ}$. Also analyzing the results, it was noted that the lineaments extracted after the hillshaded procedure display a wide range of directions. Moreover, the main directions of the lineaments coincide at different azimuths. The extracted lineaments from SRTM data are located mainly on the slopes and in the shadow area, which indicates the high sensitivity of the radar data to the geomorphology of the area. But at the same time, radar data do not allow determining the accuracy of detecting lineament structures on flat terrain.

\section{Acknowledgements}

This work was carried out within the scientific and applied project FA-A5-F014 of the Astronomical Institute of Uzbekistan with the financial support of the Ministry of Innovative Development of the Republic of Uzbekistan.

\section{REFERENCES}

1. Thannoun RG. Automatic Extraction and Geospatial Analysis of Lineaments and their Tectonic Significance in some areas of Northern Iraq using Remote Sensing Techniques and GIS. feb.-2013, vol. 2(2) 
EPRA International Journal of Economic Growth and Environmental Issues- Peer Reviewed Journal

ISSN: 2321-6247

Volume: 8 | Issue: 4 | November 2020 | Journal DOI : 10.36713/epra0713 | SJIF Impact Factor (2020): 8.007

2. Ni C, Zhang S, Liu C, Yan Y, Li Y. Lineament Length and Density Analyses Based on the Segment Tracing Algorithm: A Case Study of the Gaosong Field in Gejiu Tin Mine, China. Mathematical Problems in Engineering. 2016, 2016:1-7. doi:10.1155/2016/5392453.

3. Zlatopolskiy AA. Technique for measuring the orientation characteristics of remote sensing data (LESSA technology). Modern problems of remote sensing of the Earth from space. 2008, vol. 1(5): 102-112 (in Russian)

4. Shevyrev SL. LEFA Software: an automated structural analysis of remote sensing imagery in MATLAB environment. Earth Science. Advances in current natural science. 2018, № 10: 138-143 (in Russian)

5. Abdullah A, Nassr S, Ghaleeb A. Landsat ETM-7 for Lineament Mapping using Automatic Extraction Technique in the SW part of Taiz area, Yemen. Global Journal of HUMAN SOCIAL SCIENCE Geography, Geo-Sciences, Environmental \& Disaster Management. 2013, vol.13(3)

6. Udhi CN, Tjahjaningsih A. Lineament density information extraction using DEM SRTM data to predict the mineral potential zone. International Journal of Remote Sensing and Earth Science. 2016, vol.13(1): 67-74

7. Web-site ArcGIS for Desktop https://desktop.arcgis.com/en/arcmap/10.3/tools/ 3d-analyst-toolbox/how-hillshade-works.htm

8. Mostafa ME, Qari MYH. An exact technique of counting lineaments. Eng. Geol. 1995, 39, 5-15. 